\title{
FORMULATION AND EVALUATION OF GASTRORETENTIVE TABLETS OF ANTIULCER DRUG
}

\author{
VISHAL YADAV, PRAKASH JADHAV, PRANALI SALUNKHE*, PRITI NIKAM, SHITAL MATKAR
}

Department of Pharmaceutics, Arvind Gavali College of Pharmacy, Jaitapur, Satara, India. Email: salunkhepranali@gmail.com

Received: 16 December 2016, Revised and Accepted: 28 July 2016

\section{ABSTRACT}

Objectives: Lansoprazole is proton pump inhibitor intended for oral administration used as antiulcer agent. The objective of the present investigation was formulation and evaluation of gastroretentive floating tablets of lansoprazole for prolongation of gastric residence time with a view to deliver the drug at the sustained and controlled manner in the gastrointestinal tract.

Methods: The tablets of lansoprazole were prepared by direct compression method using gas generating agent and different polymer combinations such as hydroxypropyl methylcellulose and psyllium husk. The prepared tablets of lansoprazole were evaluated for hardness, thickness, friability, weight variation, drug content uniformity, buoyancy lag time, total floating time, swelling index, in-vitro dissolution study, etc.

Results: The varying concentration of gas generating agent and polymers was found to affect on in-vitro drug release, floating lag time, and swelling index. In vitro drug release of floating gastroretentive tablet of lansoprazole shown that the formulation $\mathrm{F}_{2}$ was found to be the best formulation as it releases $97.9 \%$ lansoprazole in a controlled manner for an extended period of time (up to $12 \mathrm{hrs}$ ).

Conclusion: Prepared floating tablets of lansoprazole may prove to be a potential candidate for safe and effective controlled drug delivery over an extended period of time for gastroretentive drug delivery system.

Keywords: Lansoprazole, Gastroretentive, Floating tablet, Total floating time.

(C) 2016 The Authors. Published by Innovare Academic Sciences Pvt Ltd. This is an open access article under the CC BY license (http://creativecommons org/licenses/by/4. 0/) DOI: http://dx.doi.org/10.22159/ajpcr.2016.v9i6.10360

\section{INTRODUCTION}

The oral route is the most convenient route for administering different protein, drugs, and bioactive agents. The gastroretentive drug delivery systems (GTDDS) can assist in improving the oral bioavailability of various pharmaceutical drugs that have an absorption window in a particular region of gastrointestinal (GI) tract [1]. The design of new oral controlled drug delivery system should be aimed toward achieving maximum pharmacological action of the drugs on targeted site. However, the development process uses to encounter several physiological difficulties such as inability to restrain and localize the DDS with desirable regions of GI tract and large variation in the gastric emptying process [2]

This variability, in turn, may lead unpredictable bioavailability and times to achieve peak plasma levels since the majority of the drugs are absorbed in the upper part of small intestine. Drug absorption from the gastrointestinal tract is a complex procedure and is subject to many variables. It is widely acknowledged that the extent of gastrointestinal tract drug absorption is related to contact time with the small intestinal mucosa [3]. Thus, small intestinal transit time is an important criterion for drugs that are incompletely absorbed. Among the various approaches, the floating DDS offer the most convenient and effective; approach to achieve increased gastric residence time and sustained drug release compared to the other methods. Based on the mechanism of buoyancy, non-effervescent and effervescent technologies have been utilized in the development of floating DDS (FDDS). Non-effervescent systems commonly use gel-forming or highly swellable cellulose type hydrocolloids. Effervescent systems utilize swellable polymers and inclusion of gas generating agents, sodium bicarbonate, and citric or tartaric acid. Lansoprazole is a proton pump inhibitor intended for oral administration used in the treatment of ulcers, Helicobacter pylori infection, gastroesophageal reflux disease, etc. Floating GTDDS is suitable for lansoprazole drug because of most common ulcers form in the lining of stomach, and or just below the stomach. Floating gastroretentive tablets of lansoprazole were prepared with an objective to increases the bioavailability and site specific and local therapy for the ulcers [4].

\section{METHODS}

Materials

Hydroxypropyl methylcellulose (HPMC K4M, HPMC K100M) was procured from Meditab Specialities Pvt. Ltd., Satara. Psyllium husk was procured from Raptakos Brett and Co. Ltd., Mumbai. Lactose was procured from Okasa Pharma Pvt. Ltd., Satara. Sodium bicarbonate, PVP K-30, Magnesium stearate, Talc were purchased from Loba Chemie, Mumbai. Lansoprazole was received as a kind gift from Cipla Pvt. Ltd., Kurkumbh.

\section{Formulation development}

\section{Preparation of matrix tablets}

The matrix tablet contains a uniform mixture of drug, polymer and other excipients including the gas-generating agent. The tablets were prepared by direct compression method. Weighed quantities of ingredients given in Table 1 . All ingredients were accurately weighed and except lansoprazole, all ingredients were passed through sieve (60\#). First, lansoprazole and swelling polymers are mixed by trituration in mortar for 10 minutes to form uniform powder. Then, PVP K-30 and sodium bicarbonate were added to ensure the uniform mixing. Then, lactose, magnesium stearate, and talc were added and mix for 10 minutes. Powder blend was compressed into tablet using 8 station tablet punching machine with $9 \mathrm{~mm}$ punch.

\section{Characterization}

\section{Evaluation of granules}

Flow properties of granules

The flow properties of granules (before compression) were characterized in terms of angle of repose, Carr's index, and Hausner's ratio. For determination of angle of repose $(\theta)$, the granules were poured through the walls of a funnel, which was fixed at a position such that its lower tip was at a height of exactly $2.0 \mathrm{~cm}$ above hard surface. The granules were poured till the time when upper tip of the pile surface touched the lower tip of funnel. The tan- 1 of (height of the pile/radius of its base) provided the angle of repose. Bulk density, 
Table 1: Formulation of matrix tablets

\begin{tabular}{|c|c|c|c|c|c|c|c|c|c|c|}
\hline \multirow[t]{2}{*}{ Ingredients } & \multicolumn{10}{|c|}{ Formulation code (quantities in $\mathrm{mg}$ ) } \\
\hline & $\mathrm{F}_{1}$ & $\mathbf{F}_{2}$ & $\mathbf{F}_{3}$ & $\mathbf{F}_{4}$ & $\mathbf{F}_{5}$ & $\mathbf{F}_{6}$ & $\mathbf{F}_{7}$ & $\mathbf{F}_{8}$ & $\mathbf{F}_{9}$ & $F_{10}$ \\
\hline Lansoprazole & 30 & 30 & 30 & 30 & 30 & 30 & 30 & 30 & 30 & 30 \\
\hline HPMC K4M & 100 & 100 & - & - & 75 & 75 & 25 & 25 & 50 & 50 \\
\hline HPMC K100M & - & - & 100 & 100 & 25 & 25 & 75 & 75 & 50 & 50 \\
\hline Psyllium husk & 30 & 30 & 30 & 30 & 30 & 30 & 30 & 30 & 30 & 30 \\
\hline Sodium bicarbonate & 60 & 40 & 60 & 40 & 60 & 40 & 60 & 40 & 60 & 40 \\
\hline PVP K-30 & 20 & 20 & 20 & 20 & 20 & 20 & 20 & 20 & 20 & 20 \\
\hline Lactose & 55 & 75 & 55 & 75 & 55 & 75 & 55 & 75 & 55 & 75 \\
\hline Magnesium stearate & 3 & 3 & 3 & 3 & 3 & 3 & 3 & 3 & 3 & 3 \\
\hline Talc & 2 & 2 & 2 & 2 & 2 & 2 & 2 & 2 & 2 & 2 \\
\hline Total weight & 300 & 300 & 300 & 300 & 300 & 300 & 300 & 300 & 300 & 300 \\
\hline
\end{tabular}

HPMC: Hydroxypropyl methylcellulose

tapped density, Carr's index, and Hausner's ratio were calculated using tap density apparatus [5-7].

\section{Evaluation of tablets}

\section{Diameter and thickness}

The diameter and thickness of tablet were measured by using a vernier caliper. It is expressed in $\mathrm{mm}$. Three tablets were selected at random from each batch and the mean, standard deviation values were calculated [8].

\section{Hardness test}

Hardness or tablet crushing strength (the force required to break a tablet in a diametric compression) was measured using a Monsanto tester. The test was performed on three tablets from each formulation, and the average reading was noted. The mean \pm standard deviation values of hardness were calculated [9].

\section{Friability test}

Friability test is performed to evaluate the ability of the tablets to withstand abrasion in packing, handling and transporting. Friability of tablets was determined using a friabilator (B.R. Instruments). Ten preweighed tablets were placed in the friabilator, operated for 4 minutes at $25 \mathrm{rpm}$. After 100 revolutions, the tablets were taken out, dedusted and reweighed. The percentage friability of tablets was measured as per the following formula [10]

$\%$ friability $=($ Initial weight-final weight $) /($ initial weight $) \times 100$

\section{Weight variation test}

It is desirable that every individual tablet in a batch should be uniform in weight, but a small variation in the weight of the individual tablet is liable to occur. Therefore, a little variation is allowed in the weight of tablet by the pharmacopoeia. The following percentage deviation in weight variation is allowed. To study weight variation, 20 tablets of each batch were weighed using an analytical electronic balance and mean weight was calculated. Not more than 2 tablets should deviate from the average weight of the tablets [11] (Table 1).

\section{In vitro buoyancy or floating studies}

In vitro buoyancy was determined by the measurement of floating lag time (FLT) and total floating time (TFT). Tablet was placed in a $100 \mathrm{ml}$ beaker containing $0.1 \mathrm{~N}$. HCL. Time required for tablet to rise on the surface of medium and float was determined as "FLT." It is expressed in seconds or minutes. The duration of time by which tablet constantly emerges on the surface of medium was determined as the "TFT." It is expressed in hrs [12-14].

\section{Swelling studies}

The swelling properties were determined by placing the tablet in the dissolution test apparatus, in $900 \mathrm{ml}$ of $0.1 \mathrm{~N} \mathrm{HCL}$ at $037 \pm 0.5^{\circ} \mathrm{C}$ rotated at $50 \mathrm{rpm}$. The tablets were removed after $12 \mathrm{hrs}$ from dissolution medium, blotted to remove excess water, and weighed. Swelling
Table 2: Relation between average tablet weight and \% deviation allowed as per IP

\begin{tabular}{ll}
\hline Average tablet weight & deviation allowed \% \\
\hline $80 \mathrm{mg}$ or less & 10 \\
More than $80 \mathrm{mg}$ but $<250 \mathrm{mg}$ & 7.5 \\
$250 \mathrm{mg}$ or more & 5 \\
\hline
\end{tabular}

characteristics of tablets were expressed in terms of percentage water uptake $(\% \mathrm{WU})$. Water uptake or swelling index of tablets was calculated using the following formula $[15,16]$.

$\% \mathrm{WU}=$ Weight of swollen tablet-initial weight of tablet/initial weight of tablet $\times 100$

\section{In vitro dissolution studies}

In vitro dissolution study was performed in USP dissolution apparatus Type II, in $900 \mathrm{ml} 0.1 \mathrm{~N} \mathrm{HCL}$ (pH 1.2), maintained at $37 \pm 0.5^{\circ} \mathrm{C}$ at a speed of $50 \mathrm{rpm}$. At suitable time intervals, aliquots ( $5 \mathrm{ml}$ ) were withdrawn and immediately replaced with equal volume of fresh dissolution medium to maintain a constant volume for drug dissolution. The samples were filtered through a $0.45 \mu$ membrane filter and diluted to a suitable concentration with $0.1 \mathrm{~N} \mathrm{HCL}$. The absorbance of these solutions was measured at $285 \mathrm{~nm}$ using a ultraviolet spectrophotometer (Dynamica Halo DB - 20). Cumulative percentage drug release was calculated using an equation obtained from a standard calibration curve [17-20].

\section{Drug release kinetic study of optimized formulation}

Drug release kinetics was obtained by applying the release data to various models such as zero order, first order, Higuchi matrix, Hixson Crowell, and Korsmeyer-Peppas model. Several kinetic models have been proposed to describe the release characteristics of a drug from matrix. The three parameters were used to study the release mechanism, i.e., release rate constant $(\mathrm{k})$, correlation coefficient $(\mathrm{R})$, and release exponent $(\mathrm{n})$ and determine the best fit model for optimized formulation [21].

\section{RESULT AND DISCUSSION}

Flow properties of granules

Flowability of granules was found to be good as indicated by compressibility flowability correlation data. Granule characterization value was given in Table 3. All these values indicate that the prepared granules exhibited good flow properties.

\section{Diameter and thickness}

Diameter and thickness of tablets of all batches were observed in between $9.05-9.09 \mathrm{~mm}$ and 4.36-4.49 $\mathrm{mm}$, respectively. Results were given in Table 4.

\section{Hardness test}

The hardness of all the tablets was found to be in the range of $4.06 \mathrm{~kg} / \mathrm{cm}^{2}-4.8 \mathrm{~kg} / \mathrm{cm}^{2}$. Results were given in Table 4 . 
Friability test

Friability was found to be $<1 \%$ indicating good mechanical resistance. Results were given in Table 4.

Weight variation test

The average weight of the prepared tablets was found to be in the range of 297.8-299.4 mg. Results were given in Table 4.

In vitro buoyancy or floating studies

The results of FLT and TFT are shown in Table 5. FLT of odd batches was found to be less as compared to even batches. A higher proportion of sodium bicarbonate shows the less FLT as well as lesser proportion of sodium bicarbonate shows the high FLT. FLT of all formulations was found to be in the range of 10-29.66 minutes. TFT of all the formulations were found to be $>12$ hrs. Photographs of in vitro buoyancy study of optimized formulation $\mathrm{F}_{2}$ as shown in Fig. 1.

\section{Swelling studies}

Results of swelling index profile are shown in Table 6. Swelling index of all formulations is varied in between $138.46 \%$ and $220.73 \%$. Swelling index of the formulation is depends on the type of polymers and amount of polymers used in that formulation.

Table 3: Characterization of granules

\begin{tabular}{|c|c|c|c|c|c|}
\hline Formulation code & Angle of $\operatorname{repose}^{*}(\theta)$ & Bulk density* $(\mathrm{gm} / \mathrm{ml})$ & Tapped density* $(\mathrm{gm} / \mathrm{ml})$ & Carr's index* $(\%)$ & Hausner's ratio* \\
\hline $\mathrm{F}_{1}$ & $22.12 \pm 0.28$ & $0.429 \pm 0.020$ & $0.500 \pm 0.028$ & $14.20 \pm 0.81$ & $1.16 \pm 0.01$ \\
\hline $\mathrm{F}_{2}$ & $23.58 \pm 0.55$ & $0.426 \pm 0.019$ & $0.505 \pm 0.027$ & $15.47 \pm 0.90$ & $1.18 \pm 0.017$ \\
\hline $\mathrm{F}_{3}^{2}$ & $21.96 \pm 0.28$ & $0.429 \pm 0.020$ & $0.502 \pm 0.025$ & $14.58 \pm 0.29$ & $1.16 \pm 0.005$ \\
\hline $\mathrm{F}_{4}^{3}$ & $22.61 \pm 0.56$ & $0.425 \pm 0.021$ & $0.506 \pm 0.025$ & $15.93 \pm 0.11$ & $1.18 \pm 0.005$ \\
\hline $\mathrm{F}_{5}$ & $22.61 \pm 0.56$ & $0.410 \pm 0.001$ & $0.474 \pm 0.002$ & $13.54 \pm 0.79$ & $1.15 \pm 0.01$ \\
\hline $\mathrm{F}_{6}$ & $23.58 \pm 0.55$ & $0.405 \pm 0.003$ & $0.479 \pm 0.001$ & $15.30 \pm 0.76$ & $1.17 \pm 0.011$ \\
\hline $\mathrm{F}_{7}^{6}$ & $22.61 \pm 0.56$ & $0.43 \pm 0.019$ & $0.500 \pm 0.028$ & $13.76 \pm 0.78$ & $1.15 \pm 0.015$ \\
\hline $\mathrm{F}_{9}^{8}$ & $22.77 \pm 0.84$ & $0.423 \pm 0.022$ & $0.493 \pm 0.030$ & $13.77 \pm 0.79$ & $1.15 \pm 0.015$ \\
\hline $\mathrm{F}_{10}$ & $23.58 \pm 0.55$ & $0.418 \pm 0.024$ & $0.497 \pm 0.030$ & $15.82 \pm 0.14$ & $1.18 \pm 0.005$ \\
\hline
\end{tabular}

*All values are expressed in mean \pm standard deviation, $\mathrm{n}=3$

Table 4: Evaluation of tablets

\begin{tabular}{|c|c|c|c|c|c|}
\hline Formulation code & Diameter* (mm) & Thickness* (mm) & Hardness* $\left(\mathrm{Kg} / \mathrm{cm}^{2}\right)$ & $\%$ friability (\%) & Weight variation $*(\mathrm{mg})$ \\
\hline $\mathrm{F}_{1}$ & $9.09 \pm 0.020$ & $4.37 \pm 0.015$ & $4.06 \pm 0.11$ & 0.67 & $299.4 \pm 0.2$ \\
\hline $\mathrm{F}_{2}$ & $9.05 \pm 0.025$ & $4.43 \pm 0.032$ & $4.6 \pm 0.11$ & 0.59 & $298.3 \pm 0.25$ \\
\hline $\mathrm{F}_{3}^{2}$ & $9.07 \pm 0.011$ & $4.40 \pm 0.011$ & $4.1 \pm 0.28$ & 0.68 & $299.1 \pm 0.15$ \\
\hline $\mathrm{F}_{4}^{3}$ & $9.08 \pm 0.01$ & $4.44 \pm 0.023$ & $4.8 \pm 0.17$ & 0.60 & $298.9 \pm 0.1$ \\
\hline$F_{5}$ & $9.07 \pm 0.015$ & $4.38 \pm 0.01$ & $4.06 \pm 0.11$ & 0.65 & $298.7 \pm 0.15$ \\
\hline $\mathrm{F}_{6}^{5}$ & $9.06 \pm 0.02$ & $4.44 \pm 0.045$ & $4.6 \pm 0.11$ & 0.60 & $297.8 \pm 0.15$ \\
\hline $\mathrm{F}_{7}$ & $9.06 \pm 0.005$ & $4.36 \pm 0.023$ & $4.3 \pm 0.26$ & 0.69 & $298 \pm 0.1$ \\
\hline $\mathrm{F}_{8}$ & $9.09 \pm 0.01$ & $4.48 \pm 0.015$ & $4.6 \pm 0.11$ & 0.57 & $298.7 \pm 0.15$ \\
\hline $\mathrm{F}_{9}^{8}$ & $9.08 \pm 0.026$ & $4.39 \pm 0.026$ & $4.06 \pm 0.11$ & 0.68 & $298.2 \pm 0.15$ \\
\hline $\mathrm{F}_{10}^{9}$ & $9.07 \pm 0.020$ & $4.49 \pm 0.025$ & $4.6 \pm 0.11$ & 0.61 & $298.9 \pm 0.1$ \\
\hline
\end{tabular}

*All values are expressed in mean \pm standard deviation, $n=3$

Table 5: Buoyancy or floating lag time and total floating time

\begin{tabular}{|c|c|c|c|c|c|c|c|c|c|c|}
\hline Formulation code & $\mathbf{F}_{1}$ & $\mathbf{F}_{2}$ & $\mathbf{F}_{3}$ & $\mathrm{~F}_{4}$ & $F_{5}$ & $F_{6}$ & $\mathbf{F}_{7}$ & $\mathrm{~F}_{8}$ & $F_{9}$ & $F_{10}$ \\
\hline FLT (Seconds)* & $10 \pm 1.73$ & $13.66 \pm 1.52$ & $15.33 \pm 0.57$ & $29.66 \pm 1.15$ & $10 \pm 1$ & $14.33 \pm 0.57$ & $22.33 \pm 0.57$ & $26.33 \pm 0.57$ & $12.33 \pm 0.57$ & $24.66 \pm 1.15$ \\
\hline TFT (hrs) & $>12$ & $>12$ & $>12$ & $>12$ & $>12$ & $>12$ & $>12$ & $>12$ & $>12$ & $>12$ \\
\hline
\end{tabular}

*All values are expressed in mean \pm standard deviation, $n=3$. FLT: Floating lag time
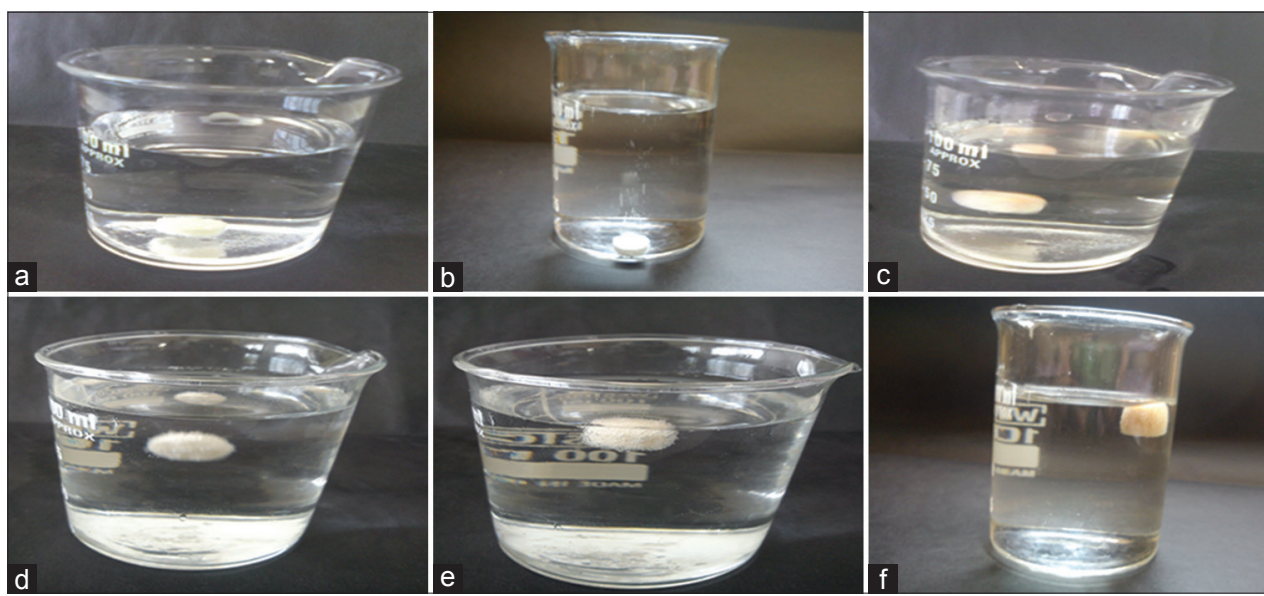

Fig. 1: Photographs of in vitro buoyancy study of optimized formulation $F_{2}$. (a) At initial time, (b) after 3 seconds, (c) after 6 seconds, (d) after 10 seconds, (e) after 13 seconds, (f) after 12 hrs 
Table 6: Swelling index

\begin{tabular}{|c|c|c|c|c|c|c|c|c|c|c|}
\hline Formulation code & $F_{1}$ & $\mathbf{F}_{2}$ & $\mathbf{F}_{3}$ & $\mathbf{F}_{4}$ & $\mathbf{F}_{5}$ & $F_{6}$ & $\mathbf{F}_{7}$ & $\mathbf{F}_{8}$ & $F_{9}$ & $F_{10}$ \\
\hline Swelling index (after $12 \mathrm{hrs)} \mathrm{( \% )}$ & 146.4 & 181.27 & 147.98 & 212.37 & 138.46 & 185.90 & 145.30 & 220.73 & 150.33 & 195.30 \\
\hline
\end{tabular}

Table 7: In vitro drug release of $F_{1}-F_{10}$ formulation

\begin{tabular}{lllllllllll}
\hline Time (after12 hrs) & \multicolumn{10}{l}{ \% cumulative drug release } \\
\hline & $\mathbf{F}_{\mathbf{1}}$ & $\mathbf{F}_{\mathbf{2}}$ & $\mathbf{F}_{\mathbf{3}}$ & $\mathbf{F}_{\mathbf{4}}$ & $\mathbf{F}_{\mathbf{5}}$ & $\mathbf{F}_{\mathbf{6}}$ & $\mathbf{F}_{\mathbf{7}}$ & $\mathbf{F}_{\mathbf{8}}$ & $\mathbf{F}_{\mathbf{9}}$ & $\mathbf{F}_{\mathbf{1 0}}$ \\
\hline & 91.36 & 97.9 & 90.9 & 94.23 & 80.03 & 84.46 & 79.9 & 83.26 & 87.16 & 90.93 \\
\hline
\end{tabular}

Table 8: Release kinetics of optimized formulation $\left(F_{2}\right)$

\begin{tabular}{lllllll}
\hline Model & Zero order & First order & Higuchi matrix & Hixson crowell & Korsmeyer-peppas & Best fit model \\
\hline $\mathrm{k}$ & 8.6694 & -0.2220 & 24.7498 & -0.0495 & 11.1448 \\
$\mathrm{R}$ & 0.9955 & 0.8512 & 0.9505 & 0.9539 & 0.9994 \\
$\mathrm{n}$ & - & - & - & - & 0.8864 & Korsmeyer-peppas model \\
\hline
\end{tabular}

All formulations containing the psyllium husk as natural polymers in same proportions and HPMC K4M, HPMC K100M used in the different formulations in different proportions. Depend on these proportions swelling profile of formulation is changed. Formulation containing psyllium husk and higher proportion of HPMC K100M shows the higher swelling index as compared to formulations containing psyllium husk and HPMC K4M, HPMC K100M shows good swelling property than HPMC K4M.

\section{In vitro dissolution studies}

The data obtained from in vitro release for formulations are tabulated in Table 7. As compared to other batches, batches containing a higher proportion of HPMC K4M with less proportion of sodium bicarbonate show maximum release. The comparison of drug release profile of all formulations, formulations $\mathrm{F}_{2}$ which contains psyllium husk and more amount of HPMC K4M with less amount of sodium bicarbonate showed maximum drug release. The maximum in vitro drug release shown by F2 formulation.

\section{Drug release kinetic study of optimized formulation}

The three parameters were used to study the release mechanism, i.e., $\mathrm{k}$, $\mathrm{R}$, and $\mathrm{n}$. Release rate constant, correlation coefficient, and release exponent of batch $\mathrm{F}_{2}$ for these models are reported in Table 8 .

The $\mathrm{n}$ value of the Korsmeyer-peppas model for $\mathrm{F}_{2}$ formulations was found to be 0.8864 indicating non-fickian diffusion principle. The model that best fits the release data were selected based on the correlation coefficient ' $R$ ' value in various models. The model that gave the high ' $R$ ' value was considered as the best fit of the release data. From the result, best fit model for optimized $F_{2}$ formulation is Korsmeyer-peppas model.

\section{CONCLUSION}

Sodium bicarbonate mainly affects on FLT, FLT was decreased by increasing the concentration of sodium bicarbonate as well as FLT was increased by decreasing the concentration of sodium bicarbonate. The formulation containing less concentration of sodium bicarbonate they show the better drug release. Higher concentration of HPMC K100M as compared to HPMC K4M, and psyllium husk they shown the high swelling index. HPMC K100M shows the higher swelling properly than HPMC K4M. Natural polymer psyllium husk also helpful for swelling, they increase the residence time in the stomach, which eventually improves the extent of bioavailability. In vitro drug release of floating gastroretentive tablet of lansoprazole shown that the formulation $\mathrm{F}_{2}$ was found to be the best formulation as it release $97.9 \%$ lansoprazole in a controlled manner with constant fashion over extended period of time (up to $12 \mathrm{hrs}$ ).
Hence, finally, it was concluded that the prepared floating gastroretentive tablet of lansoprazole may prove to be potential candidate for safe and effective controlled drug delivery over an extended period of time for GDDS.

\section{REFERENCES}

1. Chein YW. Novel Drug Delivery Systems. $2^{\text {nd }}$ ed. New York: Marcel Dekker Inc.; 1992. p. 139-1.

2. Singh BN, Kim KH. Floating drug delivery systems: An approach to oral controlled drug delivery via gastric retention. J Control Release 2000;63:235-59.

3. Brahmankar DM, Jaiswal SB. Biopharmaceutics and Pharmacokinetics a treatise. Reprint of $1^{\text {st }}$ ed. New Delhi: Vallabh Prakashan, Jain MK; 2003. p. 371-35.

4. Thomas WL, Robinson JR. In: Gennaro AR, editor. Remington: The Science and Practice of Pharmacy. 20 $0^{\text {th }}$ ed. Vol. I. Philadelphia, PA: Lippincott Williams and Wilkins; 2000. p. 929-03.

5. Pahwa R, Lamba A. Formulation and in-vitro evaluation of effervescent floating tablets of an antiulcer agent. JCPR 2012;4(2):1073-61.

6. More HN, Hajare AA. Practical Physical Pharmacy. $2^{\text {nd }}$ ed. Nasik; Career Publications; 2010. p. 126

7. Aulton ME. The Design and Manufacture of Medicines. $3^{\text {rd }}$ ed. Edinburgh: Churchill Living Stone Elsevier; 2008. p. 356.

8. Shah SH. Formulation and evaluation of effervescent floating tablet of levofloxacin against $H$. Pylori infection. Pelagia research library. Der Pharm Sin 2010;1(3):244-32.

9. Gupta AK. Introduction to Pharmaceutics-I. $3^{\text {rd }}$ ed. New Delhi: CBS Publication; 2006. p. 270-68.

10. Patel R. Formulation and optimization of floating matrix tablet of ranitidine hydrochloride. IJCP 2011;5(8):5-1.

11. Indian Pharmacopoeia. Ministry of Health and Family Welfare. $4^{\text {th }}$ ed. Vol. 1. New Delhi: Government of India. Pharmacopoeia of India, Controller of Publication; 2007. p. 183-2.

12. Kumar GG, Garuji R, Reddy CK. Formulation and evaluation of omeprazole gastroretentive floating tablets based on hydrophilic polymers. JPCBS 2012;1(1):9-6.

13. Raval JA. Formulation of floating mixed matrix tablets using low density copolymer. IRJP 2011;1(1):7-1.

14. Gaikwad VD. Development of floating drug delivery system for 5-fluorouracil. Invent Rapid 2013;2:4-1.

15. Keerthi K, Veerabhadraiah BB, Srinivasan B, Rajamanickam D, Varadharajan M. Formulation and evaluation of effervescent gastroretentive drug delivery system of Lansoprazole. Invent Impact Pharm Tech 2012;2:120-15.

16. Gaikwad VD, Yadav VD, Jadhav PD. Formulation and evaluation of floating matrix tablets of diltiazem HCL. Asian J Pharm 2012;6(4):251-45.

17. Babu GD, Chandra SR, Devi AS, Reddy BV, Latha NS. Formulation and evaluation of novel effervescent metronidazole floating tablets. Int J Res Pharm Biomed Sci 2011;2(4):1662-57.

18. Charyulu NR. Effect of combination of HPMC and carbopol $934 \mathrm{p}$ on 
the properties of the gastric floating tablets timolol malate. J Drug Deliv Ther 2013;3(4):20-5.

19. The United State Pharmacopoeia. 27 $7^{\text {th }}$ Revision and the National Formulary. $22^{\text {nd }}$ ed. The Official Compendia of Standards, Asian Edition the Board of Trustees; 2004. p. 2304-3.
20. Bhise SB, Dias RJ. Laboratory Manual of Biopharmaceutics and Pharmacokinetics. Satara: Thrinity Publishing House; 2010. p. 21.

21. Sarangapani S, Rajappan M. Lansoprazole release from a floating dosage form based on the natural polymer of Delonix regia. IJPRIF 2012;4(3):1095-84. 